\title{
Mineral dust observed with AERONET Sun photometer, Raman lidar, and in situ instruments during SAMUM 2006: Shape-dependent particle properties
}

\author{
D. Müller, ${ }^{1,2}$ A. Ansmann, ${ }^{2}$ V. Freudenthaler, ${ }^{3}$ K. Kandler ${ }^{4}$ C. Toledano, ${ }^{3,5}$ A. Hiebsch,${ }^{2}$ \\ J. Gasteiger, ${ }^{3}$ M. Esselborn, ${ }^{6}$ M. Tesche, ${ }^{2}$ B. Heese, ${ }^{2}$ D. Althausen, ${ }^{2}$ B. Weinzierl, ${ }^{6}$
}

A. Petzold, ${ }^{6}$ and W. von Hoyningen-Huene ${ }^{7}$

Received 20 May 2009; revised 27 September 2009; accepted 14 December 2009; published 5 June 2010.

[1] Nearly pure Saharan dust was observed with an Aerosol Robotic Network (AERONET) Sun photometer, several Raman and high spectral resolution lidars, and airborne in situ instruments during the Saharan Mineral Dust Experiment (SAMUM) 2006 in Morocco. In the framework of a case study we present particle shape-dependent dust properties, i.e., backscatter coefficients, extinction-to-backscatter (lidar) ratios, and linear particle depolarization ratios. These parameters can be inferred from AERONET's latest version of the mineral dust retrieval algorithm. The parameters can be measured with multiwavelength Raman/depolarization lidar without critical assumptions on particle shape. Lidar ratios inferred from the AERONET Sun photometer data tend to be larger than lidar ratios measured directly with lidar. Linear dust depolarization ratios were derived for several measurement wavelengths from the data products of the AERONET Sun photometer. The depolarization ratios tend to be smaller than the depolarization ratios measured with lidar. The largest differences exist in the near-ultraviolet wavelength range. Particle axis ratios were determined with scanning electron microscopy. The axis ratio distribution differs significantly from the axis ratio distribution that is assumed in the AERONET retrievals. If the axis ratio distributions measured during SAMUM are used, the reproducibility of the lidar data products improves. The differences may in part be caused by an insufficient understanding of the light-scattering model that is used in the AERONET algorithm. The results of the present study will be used to develop a dust light-scattering model that will serve as the theoretical basis for the inversion of optical data into dust microphysical properties.

Citation: Müller, D., et al. (2010), Mineral dust observed with AERONET Sun photometer, Raman lidar, and in situ instruments during SAMUM 2006: Shape-dependent particle properties, J. Geophys. Res., 115, D11207, doi:10.1029/2009JD012523.

\section{Introduction}

[2] This contribution is part two of our case study of 19 May 2006 [Müller et al., 2010]. In paper one, Müller et al. [2010], we present results of Saharan mineral dust properties observed with a multitude of remote sensing and in situ

\footnotetext{
${ }^{1}$ Presently at Atmospheric Remote Sensing Laboratory, Gwangju Institute of Science and Technology, Gwangju, South Korea.

${ }^{2}$ Leibniz Institute for Tropospheric Research, Leipzig, Germany.

${ }^{3}$ Meteorological Institute, Ludwig Maximilian University, Munich, Germany.

${ }^{4}$ Institut für Angewandte Geowissenschaften, Umweltmineralogie, Technische Universität Darmstadt, Darmstadt, Germany.

${ }^{5}$ Now at Departmento de Física Teórica, Atómica y Óptica, Universidad de Valladolid, Valladolid, Spain.

${ }^{6}$ Institut für Physik der Atmosphäre, Deutsches Zentrum für Luft- und Raumfahrt, Wessling, Germany.

${ }^{7}$ Institut für Umweltphysik, Universität Bremen, Bremen, Germany.

Copyright 2010 by the American Geophysical Union. 0148-0227/10/2009JD012523
}

measurement platforms. The instruments were operated in Morocco in the framework of the Saharan Mineral Dust Experiment (SAMUM) [Heintzenberg, 2009]. Müller et al. [2010] analyze dust particle properties that can be inferred from the observations without the constraint that we exactly know the shape of the mineral dust particles.

[3] In this second part we present data that are sensitive to the shape of mineral dust particles, i.e., particle backscatter coefficients, extinction-to-backscatter ratios, particle depolarization ratios, and the axis (and/or aspect) ratio. The latter parameter was inferred from analyzing thousands of particles with automated scanning electron microscopy [Kandler et al., 2009]. The other three shape-dependent parameters were measured with high accuracy at several wavelengths between 355 and $1064 \mathrm{~nm}$ with three ground-based aerosol Raman/depolarization lidars [Freudenthaler et al., 2009; Heese et al., 2009; Tesche et al., 2009] and one airborne high spectral resolution/depolarization lidar [Esselborn et al., 2009]. 
[4] Dust optical profiles [Tesche et al., 2009] show comparably low temporal and spatial invariance of the dust plume on 19 May 2006. Because of that invariance we may compare the particle shape-dependent properties collected with instruments that measured the dust plume in column integrated (Sun photometer), vertically resolved (lidar), and line like at constant altitude (in situ instruments aboard an aircraft that flew legs) mode.

[5] The shape-dependent parameters can be inferred with the latest version of the Aerosol Robotic Network (AERONET) [Holben et al., 1998] inversion algorithm for mineral dust [Dubovik et al., 2006]. Laboratory studies [Volten et al., 2001] show that the new scheme may be applicable to reproducing the lidar ratio measured with Raman lidar [Dubovik et al., 2006]. In contrast to the referenced earlier work, in this publication high-quality experimental data are used to test the robustness of the new model.

[6] Our main goal is to compare the aforementioned optical data products from the various measurement techniques. On the basis of this systematic comparison we want to develop an improved lidar data inversion algorithm [Müller et al., 1999; Veselovskii et al., 2002; Böckmann et al., 2005; Ansmann and Müller, 2005]. The original version of this lidar data inversion algorithm, and all updates following since 1998 [Müller et al., 1998] are used to infer microphysical properties such as particle effective radius and complex refractive index. Based on this information we may compute the single-scattering albedo. The disadvantage of this algorithm is that it exclusively works for particles of spherical shape. The goals of the SAMUM project and the overall importance of mineral dust in our climate system call for an upgrade of this algorithm, so that in future we can also derive microphysical properties of mineral dust from multiwavelength lidar observations.

[7] This upgrade work leaves us with the main task of choosing an appropriate model that correctly describes light-scattering properties of mineral dust. In recent years a lot of work has been done in other fields of remote sensing to identify particle shape models that are appropriate for analyzing remote sensing signals of mineral dust. AERONET Sun photometers [Dubovik et al., 2006] and the MISR (Multiangle Imaging SpectroRadiometer) satellite sensors [Kahn et al., 1997, 2009] certainly belong to the most important research activity.

[8] The work by Dubovik et al. [2006] and Kahn et al. [1997, 2009], though successful to some extent, also leaves open questions. Particularly, model development for these instruments does not consider application to lidar-derived optical properties. Computations of phase functions show strong variations in backward directions. Lidar measures the particle backscatter coefficient, the particle extinction-tobackscatter (lidar) ratio, and the linear particle depolarization at $180^{\circ}$. The constraint to $180^{\circ}$ however has never been of concern to the Sun photometer and satellite applications where we usually deal with scattering angles $<160^{\circ}$.

[9] The SAMUM 2006 data collected with the AERONET Sun photometer, several lidar systems, and airborne and ground-based in situ instruments provide us with a unique chance to test the light-scattering model of AERONET with regard to potential application to our lidar inversion algorithm. This work summarizes the current status of an ongoing process to validate/compare the data products of the various measurement platforms. The experimental data that we use for our studies underwent several steps of quality testing [Müller et al., 2010]. If our tests turn out positive, i.e., the light-scattering model is able to describe the lidar data at $180^{\circ}$ scattering angle at least to some degree of accuracy we will not have to develop a completely new particle model. Using this AERONET model would also be beneficial to another goal of our study, i.e., combining lidar with Sun photometer data in future generations of inversion algorithms.

[10] We emphasize that the aforementioned lidar data products are no standard output of the AERONET retrieval scheme, but they can be comparably easily calculated from particle size distribution, complex refractive index, phase function, and aspect ratio [Dubovik et al., 2006]. The AERONET model has never been designed for describing light-scattering properties at $180^{\circ}$.

[11] The evaluation and interpretation of the following results and their impact on the standard AERONET data products therefore needs to be done with extreme care and certainly will be reevaluated in the course of our study which will continue for several years. A lot of our work effort which is summarized in this contribution and by Müller et al. [2010] also focuses on quality assurance of data products from the various instruments. We have to make sure that we can compare in a reasonable and objective way point-like and line-like measurements which are based on highly different methodologies.

[12] In section 2 we summarize the instruments and measurement methods. In section 3 we present and discuss the results. We close with a summary and outlook in section 4 .

\section{Methodology}

[13] A detailed description of instruments, data analysis, and error estimates is given in the individual papers of the first special issue on SAMUM (Tellus, Ser. B, 61, 2009). A summary of specific measurement techniques important for this paper are presented by Müller et al. [2010].

[14] Briefly, an AERONET Sun photometer [Holben et al., $1998,2001]$ was operated next to the ground-based lidar instrumentation at Ouarzazate airport $\left(30.93^{\circ} \mathrm{N}, 6.9^{\circ} \mathrm{W}\right.$, $1133 \mathrm{~m}$ above seal level (asl)). The Sun photometer is used for aerosol observations at the Leibniz Institute for Tropospheric Research (IfT). The instrument was calibrated at NASA Goddard Space Flight Center before it was taken to Morocco. Another calibration was done after the SAMUM 2006 campaign.

[15] The Sun photometer measures solar radiance at 339, $379,441,501,675,869,940,1021$, and $1638 \mathrm{~nm}$ wavelength. Sky radiance (almucantar) measurements are done at $441,675,869$, and $1021 \mathrm{~nm}$. The data are used to retrieve aerosol optical depth, aerosol single-scattering albedo, particle volume size distribution from $0.05-15 \mu \mathrm{m}$ in particle radius, and the complex refractive index in the range from 1.33-1.6 (real part) and $0.0005 i-0.5 i$ (imaginary part) [Dubovik and King, 2000]. Additional data product is the particle phase function which describes the scattering properties of the particles. The algorithm is described by Dubovik et al. [2006]. 
[16] We equipped the instrument with a novel measurement channel at $1638 \mathrm{~nm}$ for the SAMUM campaign. The channel is expected to improve retrieval accuracy of some of the data products. The accuracy of the calibration of this channel is generally worse than for the other channels in the visible spectrum. A comparison of inversion data products inferred with and without the new channel shows that additional errors are comparably low in view of all other error sources. From the retrieved data products we can calculate the parameters we are interested in: particle backscatter coefficients, extinction-to-backscatter (lidar) ratios, and linear particle depolarization ratios.

[17] The AERONET algorithm also provides the aspect ratio. The aspect ratio the way it is used in this technique is defined as the ratio of the longest axis of the assumed ellipsoids to their shortest axis, and accounts for the orientation of the particles. In that way we obtain values $<1$ and/or $>1$. These standard distributions of the aspect ratio were derived by inverting phase matrices measured in laboratory by using AERONET-type retrieval algorithms [Dubovik et al., 2006].

[18] We operated four lidar instruments during SAMUM. Three of these systems were operated at the ground, which were the Backscatter Extinction lidar-Ratio Temperature Humidity profiling Apparatus (BERTHA) of IfT [Althausen et al., 2000; Tesche et al., 2009], and the three-wavelength Multiwavelength Lidar System (MULIS) [Freudenthaler et al., 2009] and the one-wavelength Portable Lidar System (POLIS) [Heese et al., 2009] of the University of Munich. The fourth system was a high spectral resolution lidar [Esselborn et al., 2008]. It was operated aboard the Falcon aircraft of the German Aerospace Center (DLR). The aircraft flew over the Ouarzazate ground station on several days during SAMUM.

[19] Table 2 of Müller et al. [2010] provides an overview on the data products that are measured with the lidar systems. A crucial point is the accuracy of the parameters of interest. For details of the data analysis procedure including a detailed error analysis we refer to Tesche et al. [2009], Freudenthaler et al. [2009], Esselborn et al. [2009], and Heese et al. [2009].

[20] The main reason for deploying three ground-based Raman lidar systems to Ouarzazate was the need to cover the atmospheric column as completely as possible. BERTHA, MULIS, and POLIS have different overlap functions [Wandinger and Ansmann, 2002], and we obtain different minimum heights above which trustworthy particle extinction profiles can be derived. Combining the various profiles largely compensates for this instrument effect.

[21] The SAMUM payload on board the Falcon combined the nadir-looking high spectral resolution lidar (HSRL) with instruments for in situ observations of aerosol particle microphysical and chemistry properties [Petzold et al., 2009; Weinzierl et al., 2009; Kandler et al., 2009]. Scanning electron microscopy was used to determine the axis ratio of the collected particles. We define the axis ratio as the ratio of the major to the minor axis of an ellipse fitted into the two-dimensional particle outline measured by the electron microscope. In contrast to the aspect ratio (as employed in the AERONET retrieval algorithm), the axis ratio is always $\geq 1$, as it does not take account of the ori- entation of the investigated particles. We have to keep in mind that this definition rests upon the simplification that we deal with a rotation symmetric scattering model which can be described by two rotation axes.

[22] Besides the fundamental error source that real mineral dust particles are not ellipsoids, the main source of uncertainty of the axis ratio is the unknown orientation of the particles on the sampling substrate. In this work, particles are assumed to lie flat, i.e., the height of the particle is assumed to be equal to the minor axis of the ellipse. The uncertainty of length measurements by the electron microscope is small (less than 5\%).

\section{Results}

\subsection{Summary of Results on Shape-Independent Properties}

[23] Müller et al. [2010] present particle extinction, absorption and scattering coefficients. The HSRL aboard the Falcon aircraft sounded the dust plume at and in the vicinity of the lidar/Sun photometer site at Ouarzazate. The aircraft measurements as well as the data taken with our three ground-based Raman lidars showed homogeneous conditions of the dust plume in terms of particle backscatter and extinction coefficients and particle size distributions.

[24] The extinction coefficients are commonly regarded insensitive to the specific shape of the particles. The comparison of the extinction coefficients from ground-based Raman and airborne high spectral resolution lidar agree well to the AERONET data. Extinction coefficients from airborne in situ measurements are only slightly higher than the extinction coefficients from remote sensing. Deviations are noted for the particle scattering and particle absorption coefficients. These two parameters are inferred from AERONET Sun photometer and the airborne in situ observations. We assume that most of these differences are caused by an inaccurate complex refractive index at infrared wavelengths used in the analysis of the airborne data.

[25] We also compared the complex refractive indices retrieved from the AERONET observations and inferred from single-particle analysis of thousands of individual particles. The particles were collected aboard the Falcon during overpasses over the AERONET site and at the ground at our second field site near Zagora $\left(30.23^{\circ} \mathrm{N}, 5.6^{\circ} \mathrm{W}\right)$. We find comparably good agreement of the imaginary part of the complex refractive index which is one key input parameter in the computation of the single-scattering albedo. We find good agreement for single-scattering albedo inferred from AERONET measurements and in situ measurements, if we consider the effect of particle size on this parameter [see Müller et al., 2010, Figure 9].

[26] Müller et al. [2010] conclude that the dust optical model used for the analysis of the Sun photometer data is capable of describing several important shape-independent optical parameters, i.e., extinction, scattering and absorption coefficients, and the Ångström exponents that follow from the coefficients. Thus, after this fundamental step of quality assurance, the next step lies on testing optical parameters that strongly depend on particle shape. 

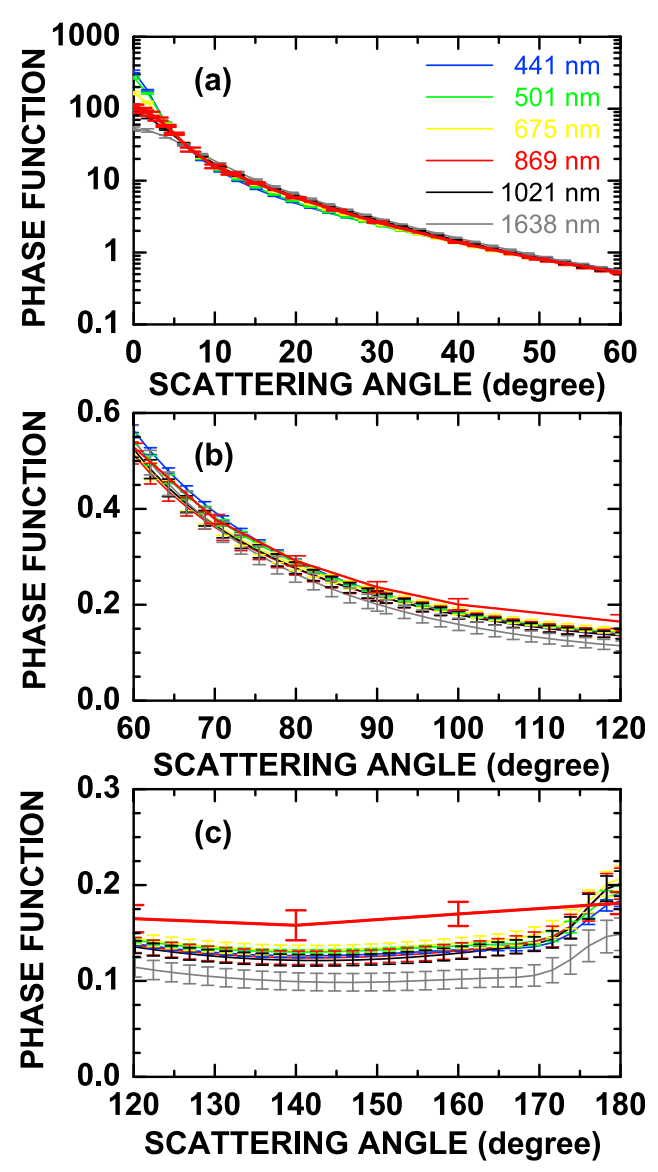

Figure 1. Particle phase functions derived from the Sun photometer measurements of sky brightness and attenuation at 441 (blue), 501 (green), 675 (yellow), 869 (red), 1021 (black), and 1638 (grey) nm. We show the phase functions for the scattering angles (a) between $0^{\circ}$ and $60^{\circ}$, (b) between $60^{\circ}$ and $120^{\circ}$, and (c) between $120^{\circ}$ and $180^{\circ}$. The traces for each wavelength represent the mean values of the phase functions determined at Ouarzazate at the time steps 0649:19,0711:50,0801:35, and 0829:46 UTC on 19 May 2006 [see also Müller et al., 2010]. The uncertainty bars present the variation of the individual phase functions (at the four time steps) in terms of 1 standard deviation. Also shown is the mean phase function obtained with a Cimel Sun photometer at $870 \mathrm{~nm}$ at the Tinfou site (thick red line).

\subsection{Particle Phase Function}

[27] Figure 1 shows the results for the particle phase functions retrieved for several wavelengths. The phase functions were calculated from the retrieved particle size distributions and complex refractive indices [Müller et al., 2010], and the shape distribution (aspect ratios) of the ellipsoids that are used in the AERONET dust particle model. The AERONET Sun photometer at Ouarzazate did not measure sky brightness at scattering angles larger than $150^{\circ}$. Values of the phase functions larger than $150^{\circ}$ scattering angle follow from extrapolation. Noteworthy is the phase function at $1638 \mathrm{~nm}$. We find significantly lower values at scattering angles above $90^{\circ}$ compared to the phase functions at the other measurement wavelengths.
[28] The extrapolation procedure can be understood if we recall how phase functions are computed. The almucantar radiance is not directly used to derive the phase function, because the radiance includes scattering, absorption and multiple scattering. The phase functions rather follow from the aerosol particle model and the inversion, via expansion coefficients that can be calculated with T-matrix and Legendre polynomials, see for instance equation (7) of Mishchenko et al. [1997] and the discussion there. The phase functions then can be calculated for the whole range of scattering angles, also at $180^{\circ}$, regardless of the fact that the measurements at scattering angles in the almucantar do not exceed $150^{\circ}$.

[29] We also show the mean phase function that was retrieved at $870 \mathrm{~nm}$ at Tinfou on 19 May 2006. The results were obtained with a Cimel Sun photometer that does not belong to AERONET [von Hoyningen-Huene et al., 2009; Dinter et al., 2009]. The station at Tinfou will be particularly important in our future studies, because measurements of sky brightness were done for scattering angles of nearly $170^{\circ}$.

[30] The mean phase function at the Tinfou site shows systematically larger values for scattering angles above approximately $90^{\circ}$, compared to the phase function at Ouarzazate. We believe that this systematic overestimation of the phase function at the Tinfou site is not caused by a difference of the particle properties at the two field sites. The atmosphere was well mixed on that day. Air was transported from the Tinfou area to the Ouarzazate site.

[31] Different light-scattering models for the nonspherical particles have been applied to the Sun photometer measurements at Tinfou and Ouarzazate. We assume that these different particle models are the most likely reason for the deviations.

[32] For the Tinfou measurements the semiempirical scattering theory of Pollack and Cuzzi [1980] as described by von Hoyningen-Huene and Posse [1997] has been used. The approach by Pollack and Cuzzi adapts the observed increase of lateral scattering in the phase function, which is caused by dust particles. This method uses an additional transmission component which can be adjusted by an asymmetry parameter. This asymmetry parameter is found by the best fit of the radiative transfer modeling of the angular sky brightness to the sky brightness measured by the sky radiometer. For the measurements at Tinfou the root mean square deviation of the fit procedure was $<5 \%$.

[33] In principle both approaches, the model by Pollack and Cuzzi [1980] and the model used by Dubovik et al. [2006], should be equivalent. The mixture of spheroids include typical features of the spheroid particle models, like the diffraction peak at $180^{\circ}$.

[34] Differences in the results from both methods can occur by the preparation of the measurement data. For the Tinfou site we use normalized sky brightness data as described by von Hoyningen-Huene et al. [2009]. In the AERONET approach that was applied to the data collected at Ouarzazate, absolute sky radiances are used. The normalized sky brightness removes calibration uncertainties, but in this way we lose the information on particle absorption. The absolute sky radiance requires a very accurate radiometric calibration. 


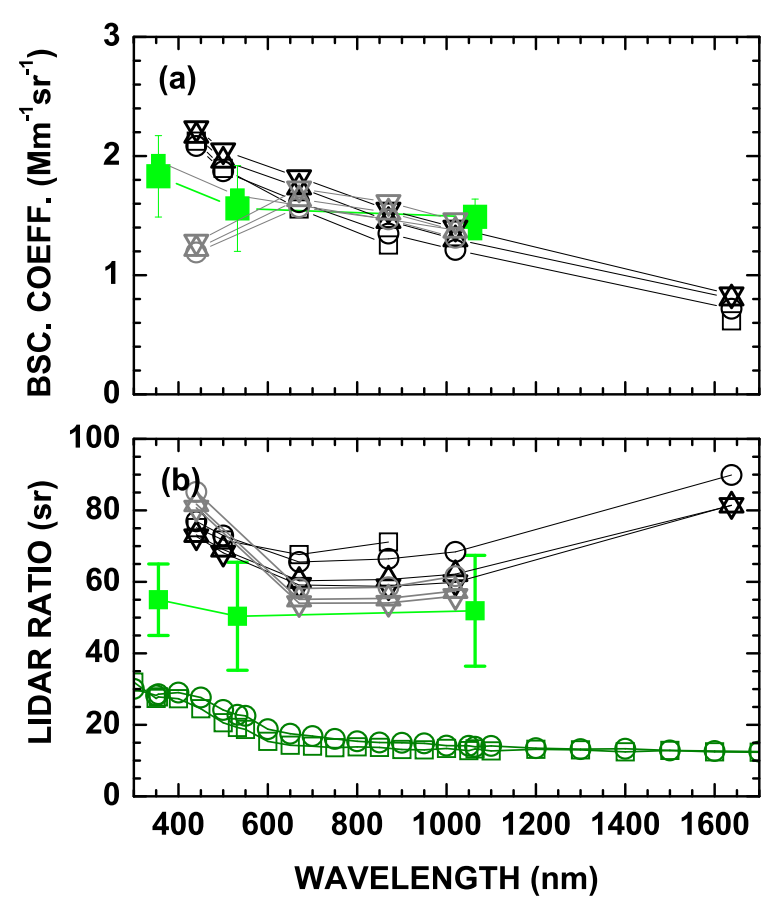

Figure 2. (a) Column mean particle backscatter coefficients (large green squares) derived with POLIS at $355 \mathrm{~nm}$ assuming a lidar ratio of $55 \mathrm{sr}$, measured with HSRL at $532 \mathrm{~nm}$, and derived with the HSRL at $1064 \mathrm{~nm}$ assuming a lidar ratio of $50 \mathrm{sr}$. Column mean particle backscatter coefficients from BERTHA (small green squares) derived at $355 \mathrm{~nm}$ (lidar ratio $=55 \mathrm{sr}$ ) and $1064 \mathrm{~nm}$ (lidar ratio $=$ $50 \mathrm{sr}$ ), and measured with the rotational Raman signals at $532 \mathrm{~nm}$. The measurement time was 0959-1116 UTC on 19 May 2006 [see also Müller et al., 2010]. Backscatter coefficients at $441,501,675,869,1021$, and $1638 \mathrm{~nm}$ were calculated from Sun photometer data according to equation (1). We present results for the four individual measurements. Black color denotes the results if the new channel at $1638 \mathrm{~nm}$ is used in data analysis. Grey color denotes that the new channel was not used. (b) Particle lidar ratios derived from POLIS $(355 \mathrm{~nm})$, BERTHA $(532 \mathrm{~nm})$, and the HSRL $(1064 \mathrm{~nm})$ and retrieved from the Sun photometer data. Also shown for illustration are results from Mie-scattering calculations on the basis of size distributions taken aboard the Falcon aircraft (dark green open squares are at $4853 \mathrm{~m}$ height asl and dark green open circles are at $3247 \mathrm{~m}$ height asl).

\subsection{Particle Backscatter Coefficient}

[35] We use the AERONET data to compute particle parameters that depend strongly on particle shape, i.e., particle backscatter coefficients, lidar ratios, and depolarization ratios. The mean geometrical thickness of the dust layer is needed to compute the mean backscatter coefficients. The results of these computations can be compared to the backscatter coefficients which are measured with our lidars. That means no assumptions on particle shape need to be made.

[36] Equation (1) shows that the particle phase function $P\left(180^{\circ} ; \lambda\right)$ at $180^{\circ}$ scattering angle and wavelength $\lambda$ is linked to the particle backscatter coefficient $\beta(\lambda)$, the particle extinction coefficient $\alpha(\lambda)$, and the single-scattering albedo $\omega(\lambda)$ in the following way:

$$
\beta(\lambda)=\frac{\alpha(\lambda) \omega(\lambda) P\left(180^{\circ} ; \lambda\right)}{4 \pi} .
$$

[37] Figure 2 shows the particle backscatter coefficient which is calculated from the Sun photometer data products according to equation (1). The dust column mean particle backscatter coefficients derived with the AERONET algorithm agree well with the lidar results for wavelengths above $\approx 675 \mathrm{~nm}$, no matter whether we use or omit in our analysis the data from the measurement channel at $1638 \mathrm{~nm}$. The backscatter coefficients that follow from the AERONET data products for wavelengths $<500 \mathrm{~nm}$ are only slightly larger than the lidar-derived values. The backscatter coefficients from AERONET are lower than the backscatter coefficients from lidar if we omit the data of the channel at $1638 \mathrm{~nm}$.

[38] Table 1 summarizes the differences of the AERONETderived backscatter coefficients, if the $1638 \mathrm{~nm}$ channel is used. We need the geometrical depth of the dust plume to scale the backscatter coefficients from the AERONET retrievals to a mean value which then can be compared to the column mean value measured with lidar; conversely we could also compare the column-integrated backscatter coefficients from lidar to the values from the AERONET measurements. The variation of the geometrical depth, as suggested by the discussion surrounding Figure 3 of Müller et al. [2010] is insufficient to account for the deviation between the AERONET and lidar data at the shorter wavelengths.

\subsection{Particle Lidar Ratio}

[39] Figure 2 also shows the column mean particle lidar ratios from the AERONET retrievals. Mean lidar ratios, and particularly the values at $441 \mathrm{~nm}$ generally tend to be higher than what was measured with lidar, regardless whether the channel at $1638 \mathrm{~nm}$ is used in data analysis or omitted, see Table 1.

[40] The lidar ratios from AERONET at 675, 869, and $1021 \mathrm{~nm}$ are well within the error bars of the lidar-derived values if we exclude the channel at $1638 \mathrm{~nm}$. As in the case of the backscatter coefficient we find noticeable deviations at the shorter wavelengths. The lidar measurements indicate a wavelength-independent lidar ratio.

Table 1. Percentage Deviation Between Particle Optical Parameters Determined From the AERONET Data Including the Measurement Channel at $1638 \mathrm{~nm}$ and Without the Channel at $1638 \mathrm{~nm}^{\mathrm{a}}$

\begin{tabular}{lcccc}
\hline \multirow{2}{*}{ Parameter } & \multicolumn{4}{c}{ Deviation at Measurement Wavelength (\%) } \\
\cline { 2 - 5 } & $441 \mathrm{~nm}$ & $675 \mathrm{~nm}$ & $869 \mathrm{~nm}$ & $1021 \mathrm{~nm}$ \\
\hline Backscatter coefficient & 41.7 & 2.0 & -8.8 & -9.3 \\
$\begin{array}{l}\text { Extinction-to-backscatter } \\
\quad \text { ratio }\end{array}$ & -8.6 & 11.9 & 12 & 10.8 \\
$\begin{array}{l}\text { Linear particle depolarization } \\
\text { ratio }\end{array}$ & 8.1 & -3.6 & -8.3 & -10.8 \\
\hline
\end{tabular}

${ }^{a}$ Positive values indicate that the respective parameter is larger if the measurement channel at $1638 \mathrm{~nm}$ is used. 
[41] The lidar ratio depends on particle shape, particle size and the complex refractive index. One way of lowering the lidar ratio is to decrease the imaginary part of the complex refractive index which in turn increases the single-scattering albedo.

[42] A decrease in the AERONET-retrieved imaginary part of the complex refractive index would however be inconsistent with Figure 5 of Müller et al. [2010]. There it is shown that the AERONET values are already moderately less than the imaginary parts derived at shorter wavelengths with absorption spectrometer [Müller et al., 2009] at Tinfou.

[43] This situation becomes even more confusing, if we return once more to the discussion of the particle backscatter coefficients that are derived from the AERONET instrument. We must keep in mind that the backscatter coefficient depends on the imaginary part of the complex refractive index and the particle shape. The lidar ratio thus could also be decreased by increasing the phase function at $180^{\circ}$, as this parameter is proportional to the particle backscatter coefficient. As mentioned the phase function at $180^{\circ}$ depends on the particle light-scattering model that is used. In that respect our results for the particle backscatter coefficients from the Sun photometer data products are a bit inconclusive, see Figure 2a. The particle backscatter coefficients at $441 \mathrm{~nm}$ wavelength are grouped around the backscatter coefficients measured with lidar at $355 \mathrm{~nm}$.

[44] So one way of lowering the AERONET derived lidar ratios in the near-UV wavelength range could be achieved if the backscatter coefficient at $441 \mathrm{~nm}$ is further increased. This requested increase of the backscatter coefficients for obvious reason only makes sense for the AERONET case in which we do no use the channel at $1638 \mathrm{~nm}$.

[45] We also need to consider the spectral dependence of the lidar ratio. The spectral feature observed in the AERONET retrieval is directly related to the spectral dependence of the retrieved single-scattering albedo. The reader will note, in reference to equation (1) that the lidar ratio is directly proportional to the inverse values of the phase function at $180^{\circ}$ and the single-scattering albedo; the fact that the former is nearly spectrally flat at the shorter wavelengths (Figure 2) means that the variation of the singlescattering albedo dominates the spectral variation of the lidar ratio at 441 and $501 \mathrm{~nm}$ [see Müller et al., 2010, Figure 8]. We stress the fact that single-scattering albedo determined from the absorption spectrometer measurements at Tinfou shows the same spectral feature.

[46] The geometry of almucantar (AERONET type) radiance measurements precludes backscattering measurements near $180^{\circ}$ scattering angle. The retrieved values of the phase function at that angle depend on the assumed shape of the size distribution. For example, the fixed aspect-ratio distribution that is used by AERONET may be different from the true one. The analysis with synthetic data carried out by Dubovik et al. [2006] did not show any significant sensitivity of the phase function at $180^{\circ}$ to the details of the aspect-ratio distribution.

[47] The changes of the phase function at $180^{\circ}$ that are caused by changes in the aspect ratio distribution are strongly correlated with the changes of the phase function in the range of scattering angles between $120^{\circ}$ and $160^{\circ}$. That correlation suggests that the spectral independence of the phase function for angles between $120^{\circ}$ and $160^{\circ}$ (note that these values are constrained by the Sun photometer observations), is an indicator of the spectral independence of the phase function at $180^{\circ}$. Direct measurements of real dust phase functions, e.g., Volten et al. [2001] suggest rather smooth and featureless phase functions at large scattering angles, which also makes strong variations of the values in backscattering directions rather unlikely.

[48] For illustration we also show results of the lidar ratio derived from Mie-scattering calculations on the basis of the particle size distributions (up to $15 \mu \mathrm{m}$ particle radius) measured aboard the Falcon aircraft on that specific day [Müller et al., 2010; Weinzierl et al., 2009]. Values drop from $30 \mathrm{sr}$ at short wavelengths $(300 \mathrm{~nm})$ to $10 \mathrm{sr}$ at the longer wavelengths $(1600 \mathrm{~nm})$. That result confirms calculations presented by Müller et al. [2003]. There it was shown that the use of spherical shape of dust particles results in a factor 2-3 lower lidar ratios.

\subsection{Particle Depolarization Ratio}

[49] The linear particle depolarization ratio strongly depends on particle shape. We calculated the depolarization ratio from the Sun photometer data with the kernel look-up tables in the fashion described by Dubovik et al. [2006].

[50] Briefly, these look-up tables allow for computing the elements of the so-called Müller scattering matrices [Bohren and Huffman, 1983]. We compute these elements from predefined values of the complex refractive index and the particle size distribution. The parameters are available from our airborne observations. Further input parameter is the frequency density distribution of the particle aspect ratio which is predefined in the standard AERONET retrieval scheme.

[51] The linear particle depolarization ratio $\delta(\lambda)$ then follows from the elements $F_{11}(\lambda)$ and $F_{22}(\lambda)$ of the Müller matrix according to

$$
\delta(\lambda)=\frac{1-F_{22}\left(\lambda, 180^{\circ}\right) / F_{11}\left(\lambda, 180^{\circ}\right)}{1+F_{22}\left(\lambda, 180^{\circ}\right) / F_{11}\left(\lambda, 180^{\circ}\right)} .
$$

The element $F_{11}$ is directly proportional to the scattering phase function.

[52] Figure 3 shows the column mean linear particle depolarization ratio measured with POLIS, MULIS, and HSRL. A detailed discussion of the depolarization ratio measurements as well as instruments and data analysis techniques are presented by Freudenthaler et al. [2009].

[53] That data set is unique as it is for the first time that particle depolarization ratios of a mineral dust plume were measured at up to four wavelengths with lidar [Freudenthaler et al., 2009]. The numbers were derived from the profiles shown in Figure 3 of Müller et al. [2010]. Regarding the measurement wavelength at $355 \mathrm{~nm}$ we could only use the data in the uppermost $1300 \mathrm{~m}$ of the dust plume. Specific instrument characteristics of the POLIS instrument did not make it possible to derive the complete profiles of the linear dust depolarization ratio. We believe, however, that the conditions in the upper part of the dust plume were very similar to the conditions below approximately $3.5 \mathrm{~km}$ height asl, because of the well-mixed state of the dust layer. 


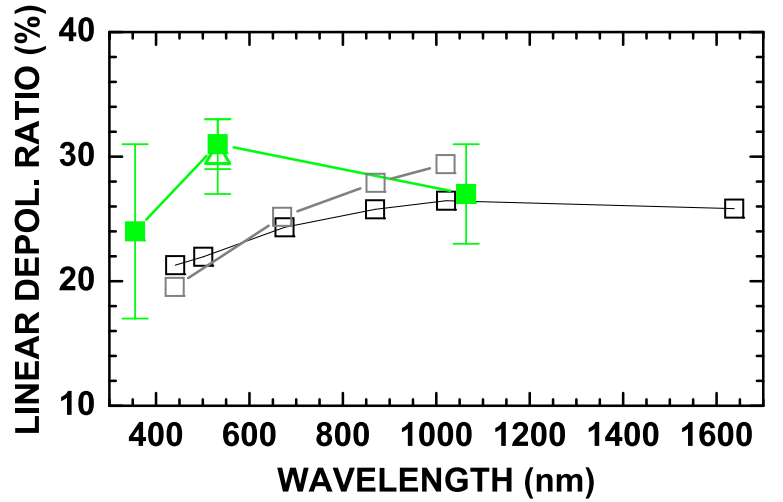

Figure 3. Linear particle depolarization ratios measured at $355 \mathrm{~nm}$ (green square is from POLIS), $532 \mathrm{~nm}$ (green square is from MULIS and green open triangle is from HSRL), and $1064 \mathrm{~nm}$ (green square is from HSRL). The data points represent the measurement on 19 May 2006. Measurement times were from 1059-1119 (POLIS), 1104-1114 (MULIS), and 1106-1112 (HSRL) UTC. The mean values were calculated from the profiles at 532 and $1064 \mathrm{~nm}$, i.e., for the height range from $1600-4200 \mathrm{~m}$ asl $(532 \mathrm{~nm})$ and from $1868-4198 \mathrm{~m}$ asl $(1064 \mathrm{~nm})$. In the case of the profile at $355 \mathrm{~nm}$ we could only use the data in the height range from 3500-4800 m asl. Error bars are taken from the column denoted as "Error" in Table 2 of Freudenthaler et al. [2009]. Column mean linear particle depolarization ratios were calculated from Sun photometer data at 441, 501, 675, 869,1021 , and $1638 \mathrm{~nm}$ according to equation (2) for the measurements at the four time steps given in Figure 1. Shown are the mean values of the four measurement times if the measurement channel at $1638 \mathrm{~nm}$ is included (open black squares). Also shown are the mean values if the new measurement channel is excluded (open gray squares).

[54] Linear particle depolarization ratios measured with lidar and retrieved with Sun photometer agree at $1064 \mathrm{~nm}$ wavelength, if we use the measurement channel at $1638 \mathrm{~nm}$ for the analysis of the Sun photometer data. The depolarization ratio is slightly overestimated, if the new channel is omitted.

[55] If we extrapolate the Sun photometer results to the lidar wavelength of $355 \mathrm{~nm}$ we find a $20 \%$ lower depolar- ization ratio from the Sun photometer data. The linear particle depolarization ratio determined from the AERONET data is approximately $22 \%$ at $501 \mathrm{~nm}$. Values around $31 \%$ at $532 \mathrm{~nm}$ are found with MULIS and HSRL. The depolarization ratio at $441 \mathrm{~nm}$ does not change significantly, if we neglect the Sun photometer channel at $1638 \mathrm{~nm}$.

[56] In summary the linear particle depolarization ratios that are inferred from the Sun photometer data at shorter wavelengths tend to be lower than the values measured with lidar. The AERONET derived numbers are higher than the measured values at longer wavelengths. The use of Sun photometer data at $1636 \mathrm{~nm}$ change the results a bit. See Table 2.

[57] The AERONET particle model does not reproduce the spectral peak in the depolarization ratio that is observed at $532 \mathrm{~nm}$. The question remains if this pronounced peak really exists. If we take all lidar observations of SAMUM 2006 we again see this peak in the spectral variation of the linear particle depolarization ratio [see Freudenthaler et al., 2009, Figure 7]. However, we need to consider the relatively high error bars and the fact that instrument performance was not optimal regarding depolarization ratio measurements.

[58] The spheroid particle model suggests a rather smooth spectral dependence of the depolarization ratios. We assume that the slight monotonic spectral changes are likely determined by the spectral dependencies of the real and imaginary part of the complex refractive index [Müller et al., 2010].

[59] We have to make two specific comments regarding the error bars. First, error bars from lidar are commonly considered as uncertainties due to statistical noise, and the true mean value is assumed to be close to the apparent mean with a probability given by the statistical nature of the signals, which often is assumed to be gaussian. In Figure 3 the error bars from lidar represent pure systematic uncertainties due to temporally constant system errors during the measurements. Thus the true profiles can be shifted anywhere inside the error bars with the same probability. The direct comparison of the two lidars at $532 \mathrm{~nm}$ serve as a quality assurance of both systems and shows the meaningfulness of the error analysis.

[60] This level of confidence in the error analysis also holds for the depolarization ratio measured with the HSRL system at $1064 \mathrm{~nm}$, as these values are measured with the same lidar and analyzed with the same error propagation

Table 2. Particle Lidar Ratios and Linear Particle Depolarization Ratios ${ }^{\mathrm{a}}$

\begin{tabular}{lcccccc}
\hline & \multicolumn{3}{c}{ Linear Particle Depolarization Ratios (\%) } & & \multicolumn{2}{c}{ Lidar Ratios (sr) } \\
\cline { 2 - 5 } $\begin{array}{c}\text { Wavelength } \\
(\mathrm{nm})\end{array}$ & Lidar & $\begin{array}{c}\text { Original } \\
\text { AERONET }\end{array}$ & $\begin{array}{c}\text { Falcon } \\
\text { AERONET }\end{array}$ & $\begin{array}{c}\text { Falcon } \\
\text { Forward }\end{array}$ & Lidar & $\begin{array}{c}\text { Original } \\
\text { AERONET }\end{array}$ \\
\hline 355 & 24 & 20 & 23 & 24 & 55 & 83 \\
Falcon \\
441
\end{tabular}

\footnotetext{
${ }^{\text {a }}$ Shown are the values measured with lidar and the original results from the AERONET retrievals (denoted by Original AERONET; only mean values are given), see Figures $2 \mathrm{~b}$ and 3. Falcon AERONET denotes the results for the linear particle depolarization ratios, if we use the axis ratio distribution measured aboard the Falcon and the scattering matrix look-up tables of Dubovik et al. [2006]. Falcon Forward denotes the results of our forward computations using the T-matrix theory.
} 


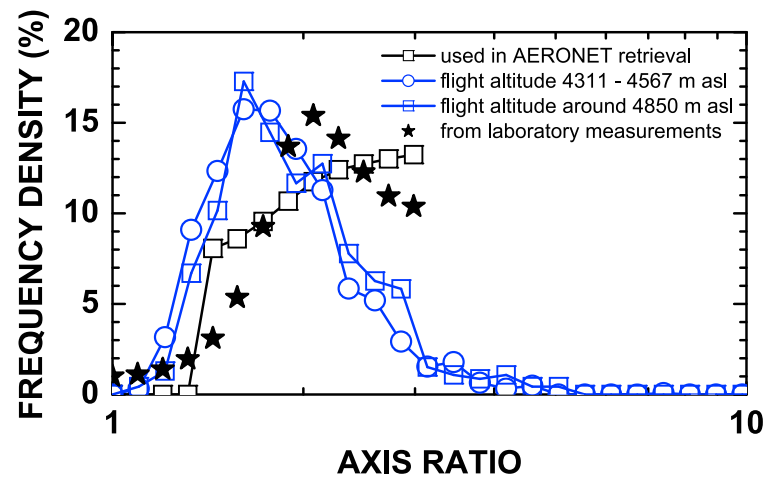

Figure 4. Frequency density distribution of axis ratios derived from the AERONET retrieval (open black squares). Also shown is the frequency plot of axis ratios of single particles collected aboard the Falcon aircraft during two overpasses over the AERONET site. We analyzed 1232 particles collected between 1125 and 1129 UTC (open blue squares) and we analyzed 463 particles that were collected between 1452 and 1454 UTC (open blue circles). The flight altitude was between 4849 and $4851 \mathrm{~m}$ asl during the first overpass and between 4311 and $4567 \mathrm{~m}$ asl during the second overpass. The radius range of the analyzed particles is between 0.35 and $2 \mu \mathrm{m}$. For details of the analysis see Kandler et al. [2009]. Also shown is the axis-ratio distribution measured under laboratory conditions (stars). For details we refer to Dubovik et al. [2006].

scheme (relative to the $532 \mathrm{~nm}$ results). The errors are large at $355 \mathrm{~nm}$ (POLIS), and comparing the POLIS profiles to the profiles from the other lidar instruments, a rangedependent signal deviation seems probable. The statistical uncertainty, which may result from the natural variation of the linear particle depolarization ratio during the measurement time was found to be considerably lower than the systematic uncertainty shown in Figure 3.

[61] Second, we do not yet have a realistic way of calculating error bars for the depolarization ratios from Sun photometer. It may well be that the deviations to the lidar depolarization ratios may become insignificant, if uncertainty levels are considered. We shall therefore process several more measurement cases in the same fashion as described in this contribution. We hope to obtain a rough estimate of the uncertainties from such an analysis. It is clear that future work will require us to develop a scheme of error estimation.

\subsection{Aspect Ratio}

[62] Figure 4 shows the distribution of axis ratios that is used for the analysis of the AERONET data. We compare this distribution to the results of the particle axis ratios determined with scanning electron microscopy. Particles were collected during two overpasses of the FALCON aircraft over the AERONET site on 19 May 2006.

[63] As mentioned in section 2 the axis ratio describes the ratio of the longest axis of the particles to their shortest axis, without taking account of the orientation of the particles. Thus, by definition, we only obtain numbers larger than one. In contrast, the aspect ratio that is used in the AERONET retrieval algorithm generates numbers smaller than one, too. We converted the aspect ratio distribution to the axis ratio distribution for representation purpose. This conversion is not difficult as the aspect ratio distribution is symmetrical with respect to the aspect ratio of unity [Dubovik et al., 2006].

[64] We use the fixed distribution function of the aspect ratio as proposed by Dubovik et al. [2006]. First, these authors show that the sensitivity to the details of the frequency density distribution of the aspect ratio is low. Second, the use of a distribution function that is assumed a priori saves computation time [Dubovik et al., 2006]. Figure 4 for comparison shows the example of a distribution function that was obtained from laboratory measurements [Dubovik et al., 2006].

[65] The frequency density distribution of the axis ratios of the AERONET model differs from the frequency density distribution derived with single-particle analysis. In the current version of the AERONET algorithm axis ratios larger than 3 are not considered. The value 3 also presents the maximum value on the frequency distribution. In contrast, the peak of the single-particle analysis frequency density distribution occurs at approximately 1.6. The maximum radius of analyzed particles is $2 \mu \mathrm{m}$. At Tinfou ground station, axis ratios were also determined for particles larger than $2 \mu \mathrm{m}$. Typically the axis ratio for these larger particles does not increase [Kandler et al., 2009].

[66] In view of the difference of the axis ratio distributions we ran two more tests. We tested how much the linear particle depolarization ratios and the particle lidar ratios change, if we use the aspect ratio distributions measured by the in situ instruments.

[67] We converted the axis ratio distribution measured aboard the Falcon aircraft into an aspect ratio distribution, simply by using the axis ratio value 1 (spherical particles) as mirror point. On that basis we computed the axis ratios $<1$. The linear particle depolarization ratios then were computed on the basis of the AERONET look-up tables and scattering matrices.

[68] Table 2 shows these new depolarization ratios for the case that we exclude the new measurement channel at $1638 \mathrm{~nm}$ in the AERONET data set. The depolarization ratio increases at $441 \mathrm{~nm}$, and to our opinion leads to a better match with the measured depolarization ratio at $355 \mathrm{~nm}$. For the longer wavelengths we note a slight decrease of the depolarization ratios. This decrease is very small in view of the overall uncertainties, but in summary we find that the comparably strong increase of the linear particle depolarization ratio with increasing wavelength, as seen in the original AERONET results, is reduced.

[69] We must point out, however, that we had to apply one constraint in our computations of these depolarization ratios. The version of the look-up scattering matrices that we use for our computations does not permit us to include axis ratios larger 3 and/or less than $1 / 3$. We had to cut the airborne-measured frequency distribution of aspect ratios above 3 and below 1/3. We assume that this cut-off restricts our computed linear particle depolarization ratios.

[70] Because of that restriction in axis ratios we ran another test. We computed particle lidar ratios and linear depolarization ratios of dust from T-matrix theory [Mishchenko et al., 1997]. Details of the simulation procedures are pre- 
sented by Wiegner et al. [2009]. We used both aspect ratio distributions by Dubovik et al. [2006] and measured by Kandler et al. [2009]. These tests are preliminary as we could not yet generate exactly the same kernel files that are used by Dubovik et al. [2006]. In using our own kernel files (computed from T-matrix theory) we introduce some uncertainty but we are confident that we obtain the correct trend of change of the investigated parameters.

[71] Table 2 summarizes the particle lidar ratios and depolarization ratios for the case of the forward modeling. We note an increase of the linear particle depolarization ratios at 441 and $675 \mathrm{~nm}$, which puts the linear particle depolarization ratios closer to the values measured with lidar. However, at 875 and $1021 \mathrm{~nm}$ we obtain even higher depolarization ratios than before.

[72] We see that the lidar ratios at the four standard wavelengths of the almucantar measurements drop by approximately $20 \%-30 \%$ at all four wavelengths. This change puts the lidar ratios at $441 \mathrm{~nm}$ considerably closer to the lidar ratios measured at 355 and $532 \mathrm{~nm}$, see Figure 2. But the drop of the lidar ratios at the other three wavelengths $(675,875$, and $1021 \mathrm{~nm})$ moves the modeled values out of the measured range of lidar ratios. In summary we must state that our forward modeling gives us improvements at the shorter wavelengths, but results become worse at the longer wavelengths [see also Wiegner et al., 2009].

[73] A more detailed analysis of the change of the shapedependent parameters that follow from the axis ratio distributions (airborne and AERONET model) with the AERONET retrieval scheme and the T-matrix forward computations needs to be left for a future contribution. We need considerably more test cases. One important task will be to find an improved computation scheme in which we can include the complete axis ratio distributions measured aboard the aircraft.

\section{Summary}

[74] In this second part of our case study we investigate data products that describe light-scattering characteristics of mineral dust at $180^{\circ}$, i.e., particle backscatter coefficients, particle lidar ratios and linear particle depolarization ratios. The main goal is to use the AERONET or a modified version of this light-scattering model for the retrieval of microphysical properties of dust from the inversion of optical data collected with multiwavelength aerosol Raman/ depolarization lidar. We shall use the inversion algorithm described by Müller et al. [1999, 2001]. In our study we compare data products that strongly depend on particle shape. We want to test if the AERONET light-scattering model can be used to describe the light-scattering properties of mineral dust for the case of a scattering angle of $180^{\circ}$. We emphasize that the AERONET light-scattering model has never been designed for applications in which light scattering at $180^{\circ}$ is involved.

[75] Dust layer integrated particle backscatter coefficients from AERONET Sun photometer agree comparably well to the values measured with lidar at the longer wavelengths (675-1064 nm), regardless whether the AERONET measurement channel at $1638 \mathrm{~nm}$ is used or omitted in data analysis. The backscatter coefficients from Sun photometer tend to be higher than the lidar-measured values at the shorter measurement wavelengths (355-532 nm), if the new AERONET channel at $1638 \mathrm{~nm}$ is used. The spectral slope of this parameter is lower than the spectral slope that follows from the lidar measurements. In contrast we find a strong drop of the backscatter coefficient at near UV wavelengths $(441 \mathrm{~nm})$ if we exclude the AERONET measurement channel at $1638 \mathrm{~nm}$.

[76] The lidar observations indicate a nearly wavelengthindependent lidar ratio. For comparison, the particle lidar ratios retrieved from the AERONET data always tend to be larger. However, the lidar ratios still agree reasonably well at 532 and $1064 \mathrm{~nm}$, if we consider error bars from lidar. We find significantly higher AERONET lidar ratios at the shorter wavelengths (near the UV) compared to the lidar data (at $355 \mathrm{~nm})$.

[77] The differences between lidar and the AERONET instrument become more obvious for the linear dust depolarization ratio. The AERONET particle depolarization ratio monotonously increases with increasing wavelength. In contrast the lidar observations suggest a maximum depolarization ratio around $532 \mathrm{~nm}$, and lower values at smaller and larger measurement wavelengths. This spectral feature is also obvious if all our depolarization ratio measurements are taken together [see Freudenthaler et al., 2009, Figure 7]. However, the ground-based instruments were not optimized regarding depolarization ratio measurements. We expect depolarization ratios with significantly higher quality from our second field campaign which was carried out in the Republic of Cap Verde in 2008.

[78] The axis ratio distribution that we find from scanning electron microscopy is rather different from the one used by default in the AERONET retrieval. We need further testing to evaluate the importance of this difference to the AERONET axis ratio distribution. On the one hand, Dubovik et al. [2006] demonstrate that the scattering matrix of desert dust can be satisfactorily reproduced by a mixture of spheroids that are dominated by aspect ratios larger than $\approx 1.4$. The details of the aspect ratio distribution for aspect ratios $>1.4$ do not change the scattering matrix significantly. For example, scattering matrices of the spheroid mixtures with the two different aspect ratio distributions shown in Figure 4 may reproduce the Sun photometer observations nearly equivalently well.

[79] On the other hand we want to apply this lightscattering model to the inversion of optical data collected with lidar. There remains the question to what accuracy we must know the aspect ratio distribution for lidar applications where we measure the phase function at $180^{\circ}$. For instance we find that using the aspect ratio distributions measured onboard the Falcon aircraft on 19 May 2006 shifts the lidar ratios to lower values and the linear dust depolarization ratios to higher values than what is implied by the axis ratio model used by Dubovik et al. [2006]. This result however is very preliminary. More refined tests for more measurement cases are needed to confirm this finding.

[80] To summarize all above arguments, the spheroidbased model cannot reproduce some of the spectral variability suggested by the lidar measurements. We emphasize that we do not yet have a reasonable calculation scheme that provides error bars from the Sun photometer data products. We need to find out under which circumstances this possible shortcoming of the spheroid parametrization of light scat- 
tering of desert dust has impact on dust characterization with remote sensing methods. Particularly the parameters retrieved from AERONET at $441 \mathrm{~nm}$ wavelength on average agree worse to the same parameters measured with lidar. Mineral dust is strongly light absorbing at ultraviolet wavelengths, and therefore it is particularly important for us to understand the reasons for the observed deviations. As shown in Figure 5 of Müller et al. [2010] the AERONET retrieval results in imaginary parts which are similar to the values inferred by the other SAMUM 2006 platforms. When we look at the results in more detail we note that the imaginary parts from AERONET are on average lower at short wavelengths, compared to the results from the other platforms. However if we increase the imaginary part of the AERONET results we would increase the AERONETderived lidar ratio at $441 \mathrm{~nm}$ even further. This increase could maybe compensated for using axis ratios larger than 3 .

[81] In contrast to the smooth spheroid model, real particles possess rough surfaces. Rough, randomly distributed features at the particles' surfaces usually result in even more featureless phase functions. Thus it is unlikely that rough surfaces introduce additional spectral features. The use of rough surfaces thus might take away some of the increase of the lidar ratio at short wavelengths.

[82] Dubovik et al. [2006] presents calculations of phase functions on the basis of Mie-scattering theory and compares the data products to results based on the spheroidal particle model. It is shown that in general the phase function is flat for spheroids, and this flatness generally remains to $180^{\circ}$ scattering angle, i.e., the authors do not observe extraordinary features of the phase functions. Moreover, most of the direct measurements of the phase function [Volten et al., 2001; Dubovik et al., 2006, and references therein] show that the phase function of real dust is rather flat at scattering angles $>60^{\circ}$. These measurements do not include $180^{\circ}$ scattering angle, but they stop rather close to $180^{\circ}$ scattering angle. If we assume that the spheroidal particle model is incorrect, we actually would have to conclude that the real phase function would be even flatter.

[83] Dubovik et al. [2006] also tested the spectral dependence of the phase function at large scattering angles. It is nearly spectrally independent for larger particles (for calculations with Mie-scattering theory and spheroid particle shape), and we assume that this shape independence is a general feature, i.e., shape independent.

[84] Another explanation of the discrepancies with regard to the spectral variations may be measurement errors that may not have been accounted for in the analysis of the experimental data, and which may falsely indicate enhanced spectral features of measured optical characteristics of dust. We expect that future studies will help us to understand these differences between modeling and measurements.

[85] What makes the interpretation of our current results even more complicated is the following fact. If we compare our results to results from an older study [Müller et al., 2003] we find improvements with this new version of the AERONET dust-particle model. In that older study we observed a Saharan dust plume over Leipzig $\left(51.3^{\circ} \mathrm{N}\right.$, $\left.12.4^{\circ} \mathrm{E}\right)$. AERONET Sun photometer observations at that time resulted in a factor two lower lidar ratios at $532 \mathrm{~nm}$ than measured with our stationary Raman lidar. The lidar ratio derived from the Sun photometer at IfT followed from the first version of the dust model of nonspherical particle geometry [Dubovik et al., 2002]. We applied the new version of the dust model to the data from this previous study. We now find good agreement of the lidar ratio derived with both instruments [Dubovik et al., 2006]. In that respect it is not clear why the lidar ratio at 355 cannot be reproduced equivalently well.

[86] Acknowledgments. This work was funded by the Korea Meteorological Administration Research and Development Program under grant CATER 2009-3112. The SAMUM consortium was funded by the German Research Foundation (Deutsche Forschungsgemeinschaft) within the Research Group SAMUM under grant FOR 539. We thank Oleg Dubovik and the AERONET team at Goddard Space Flight Center for providing us with high-quality Sun photometer results. We are grateful to the Moroccan Ministry for Foreign Affairs and the Ministry of the Interior for the permission to carry out the SAMUM field campaign in Morocco. We thank the Moroccan Airport Authority and in particular respectable Monsieur Mohammed El Mardi, commander of Ouarzazate airport, for their extraordinary support of the participants of SAMUM. Detlef Müller would like to thank L. T. for contributing to this work.

\section{References}

Althausen, D., D. Müller, A. Ansmann, U. Wandinger, H. Hube, E. Clauder, and S. Zörner (2000), Scanning 6-wavelength 11-channel aerosol lidar, J. Atmos. Ocean. Tech., 17, 1469-1482.

Ansmann, A., and D. Müller (2005), Lidar and atmospheric aerosol particles, in Lidar: Range-Resolved Optical Remote Sensing of the Atmosphere, edited by C. Weitkamp, pp. 105-141, Springer, New York.

Böckmann, C., I. Miranova, D. Müller, L. Scheidenbach, and R. Nessler (2005), Microphysical aerosol parameters from multiwavelength lidar, J. Opt. Soc. Am. A, 22, 518-528.

Bohren, C. F., and D. R. Huffman (Eds.) (1983), Absorption and Scattering of Light by Small Particles, 530 pp., John Wiley, Hoboken, N. J.

Dinter, T., W. von Hoyningen-Huene, J. P. Burrows, A. Kokhanovsky, E. Bierwirth, M. Wendisch, D. Müller, R. Kahn, and M. Diouri (2009), Retrieval of aerosol optical thickness for desert conditions using MERIS observations during the SAMUM campaign, Tellus Ser. B, 61, 229-238.

Dubovik, O., and M. D. King (2000), A flexible inversion algorithm for retrieval of aerosol optical properties from sun and sky radiance measurements, J. Geophys. Res., 105, 20,673-20,696.

Dubovik, O., B. N. Holben, T. Lapyonok, A. Sinyuk, M. I. Mishchenko, P. Yang, and I. Slutsker (2002), Non-spherical aerosol retrieval method employing light scattering by spheroids, Geophys. Res. Lett., 29(10), 1415, doi:10.1029/2001GL014506.

Dubovik, O., et al. (2006), The application of spheroid models to account for aerosol particle nonsphericity in remote sensing of desert dust, J. Geophys. Res., 111, D11208, doi:10.1029/2005JD006619.

Esselborn, M., M. Wirth, A. Fix, M. Tesche, and G. Ehret (2008), Airborne high spectral resolution lidar for measuring aerosol extintion and backscatter coefficients, Appl. Opt., 47, 346-358.

Esselborn, M., M. Wirth, A. Fix, B. Weinzierl, K. Rasp, M. Tesche, A. Petzold, and G. Ehret (2009), Spatial distribution and optical properties of Saharan dust observed by airborne high spectral resolution lidar during SAMUM 2006, Tellus Ser. B, 61, 131-143.

Freudenthaler, V., et al. (2009), Depolarization-ratio profiling at several wavelengths in pure Saharan dust during SAMUM 2006, Tellus Ser. B, $61,165-179$

Heese, B., D. Althausen, T. Dinter, M. Esselborn, T. Müller, M. Tesche, and M. Wiegner (2009), Vertically resolved dust optical properties during SAMUM: Tinfou compared to Ouarzazate, Tellus Ser. B, 61, 195-205.

Heintzenberg, J. (2009), The SAMUM-1 experiment over Southern Morocco: Overview and introduction, Tellus Ser. B, 61, 2-11.

Holben, B. N., et al. (1998), AERONET-A federated instrument network and data archive for aerosol characterization, Remote Sens. Environ., 66, $1-16$

Holben, B. N., et al. (2001), An emerging ground-based aerosol climatology: Aerosol optical depth from AERONET, J. Geophys. Res., 106, 12,067-12,097.

Kahn, R., R. West, D. McDonald, B. Rheingans, and M. I. Mishchenko (1997), Sensitivity of multiangle remote sensing observations to aerosol sphericity, J. Geophys. Res., 102, 16,861-16,870. 
Kahn, R., et al. (2009), Desert dust aerosol air mass mapping in the western Sahara, using particle properties derived from space-based multi-angle imaging, Tellus, Ser. B, 61, 239-251.

Kandler, K., et al. (2009), Size distribution, mass concentrations, chemical and mineralogical composition, and derived optical parameters of the boundary layer at Tinfou, Morocco, during SAMUM 2006, Tellus Ser. $B, 61,32-50$.

Mishchenko, M. I., L. D. Travis, R. A. Kahn, and R. A. West (1997), Modeling phase functions for dustlike tropospheric aerosols using a shape mixture of randomly oriented polydisperse spheroids, J. Geophys. Res., $102,16,831-16,847$.

Müller, D., U. Wandinger, D. Althausen, I. Mattis, and A. Ansmann (1998), Retrieval of physical particle properties from lidar observations of extinction and backscatter at multiple wavelengths, Appl. Opt., 37, 2260-2263.

Müller, D., U. Wandinger, and A. Ansmann (1999), Microphysical particle parameters from extinction and backscatter lidar data by inversion with regularization: Theory, Appl. Opt., 38, 2346-2357.

Müller, D., U. Wandinger, D. Althausen, and M. Fiebig (2001), Comprehensive particle characterization from three-wavelength Raman-lidar observations, Appl. Opt., 40, 4863-4869.

Müller, D., I. Mattis, U. Wandinger, D. Althausen, A. Ansmann, O. Dubovik, S. Eckhardt, and A. Stohl (2003), Saharan dust over a central European EARLINET-AERONET site: Combined observations with Raman lidar and Sun photometer, J. Geophys. Res., 108(D12), 4345, doi:10.1029/ 2002JD002918.

Müller, T., A. Schladitz, A. Maßling, N. Kaaden, A. Wiedensohler, and K. Kandler (2009), Spectral absorption coefficients and imaginary parts of refractive indices of Saharan dust during SAMUM-1, Tellus Ser. B, 61, 79-95.

Müller, D., et al. (2010), Mineral dust observed with AERONET Sun photometer, Raman lidar, and in situ instruments during SAMUM 2006 Shape-independent particle properties, J. Geophys. Res., 115, D07202, doi:10.1029/2009JD012520.

Petzold, A., et al. (2009), Saharan dust refractive index and optical properties from aircraft-based observations during SAMUM 2006, Tellus Ser. B, 61, $118-130$.

Pollack, J. B., and J. N. Cuzzi (1980), Scattering by nonspherical particles of size comparable to a wavelength: A new semi-empirical theory and its applications to tropospheric aerosols, J. Atmos. Sci., 37, 861-881.

Tesche, M., et al. (2009), Vertical profiling of Saharan dust with Raman lidars and airborne HSRL in southern Morocco during SAMUM, Tellus Ser. $B, 61,144-164$.

Veselovskii, I., A. Kolgotin, V. Griaznov, D. Müller, U. Wandinger, and D. N. Whiteman (2002), Inversion with regularization for the retrieval of tropospheric aerosol parameters from multiwavelength lidar sounding, Appl. Opt., 41, 3685-3699.

Volten, H., O. Munoz, E. Rol, J. F. de Haan, W. Vassen, J. W. Hovenier, K. Muinonen, and T. Nouisainen (2001), Scattering matrices of mineral aerosol particles at 441.6 and $632.8 \mathrm{~nm}, J$. Geophys. Res., 106, 17,37517,401 .

von Hoyningen-Huene, W., and P. Posse (1997), Non-sphericity of aerosol particles and their contribution to radiative forcing, J. Quant. Spectrosc. Radiat. Transfer, 57, 651-668.

von Hoyningen-Huene, W., T. Dinter, A. A. Kokhanovsky, J. P. Burrows, M. Wendisch, E. Bierwirth, D. Müller, and M. Diouri (2009), Measurements of desert dust optical characteristics at Porte au Sahara during SAMUM, Tellus Ser. B, 61, 206-215.

Wandinger, U., and A. Ansmann (2002), Experimental determination of the lidar overlap profile with Raman lidar, Appl. Opt., 41, 511-514.

Weinzierl, B., A. Petzold, M. Esselborn, M. Wirth, K. Rasp, K. Kandler, L. Schütz, P. Köpke, and M. Fiebig (2009), Airborne measurements of dust layer properties, particle size distribution and mixing state of Saharan dust during SAMUM 2006, Tellus Ser. B, 61, 96-117.

Wiegner, M., et al. (2009), Numerical simulations of optical properties of Saharan dust aerosols with emphasis on linear depolarization ratio, Tellus Ser. B, 61, 180-194.

D. Althausen, A. Ansmann, B. Heese, A. Hiebsch, D. Müller, and M. Tesche, Leibniz Institute for Tropospheric Research, Permoserstr. 15, D-04318 Leipzig, Germany. (dietrich@tropos.de; albert@tropos.de; heese@tropos.de; hiebsch@tropos.de; detlef@tropos.de; tesche@tropos. de)

M. Esselborn, A. Petzold, and B. Weinzierl, Institut für Physik der Atmosphäre, Deutsches Zentrum für Luft- und Raumfahrt, Oberpfaffenhofen, D-82234 Wessling, Germany. (michael.esselborn@dlr.de; andreas.petzold@ dlr.de; bernadett.weinzierl@dlr.de)

V. Freudenthaler and J. Gasteiger, Meteorological Institute, Ludwig Maximilian University, Theresienstr. 37, D-80333 Munich, Germany. (volker.freudenthaler@meteo.physik.uni-muenchen.de; seppg@meteo. physik.uni-muenchen.de)

K. Kandler, Institut für Angewandte Geowissenschaften, Umweltmineralogie, Technische Universität Darmstadt, D-64287 Darmstadt, Germany. (kzk@gmx.de)

C. Toledano, Departmento de Física Teórica, Atómica y Óptica, Universidad de Valladolid, Prado de la Magdalena s/n, E-47071 Valladolid, Spain. (toledano@goa.uva.es)

W. von Hoyningen-Huene, Institut für Umweltphysik, Universität Bremen, Otto-Hahn-Allee 1, D-28359 Bremen, Germany. (hoyning@iup. physik.uni-bremen.de) 